\title{
First line Treatment of Traumatic Carotid Cavernous Fis- tulas Using Covered Stents at Level 1 Regional Trauma Center
}

\author{
Sang Hoon Jeong, Jung Hwan Lee, Hyuk Jin Choi, Byung Chul Kim, Seung Han Yu, Jae II Lee \\ Department of Neurosurgery and Medical Research Institute, Pusan National University Hospital, Pusan National University School of Medi- \\ cine, Busan, Korea
}

Objective : The widely accepted treatment option of a traumatic carotid cavernous fistula (TCCF) has been detachable balloon or coils based fistula occlusion. Recently, covered stent implantation has been proving an excellent results. The purpose of this study is to investigate our experiences with first line choice of covered stent implantation for TCCF at level 1 regional trauma center.

Methods : From November 2004 to February 2020, 19 covered stents were used for treatment of 19 TCCF patients. Among them, 15 cases were first line treatment using covered stents. Clinical and angiographic data were retrospectively reviewed.

Results : Procedures were technically successful in all 15 cases (100\%). Immediate angiographic results after procedure were total occlusion in 12 patients (80\%). All patients except two expired patients had image follow-up (mean 15 months). Recurred symptomatic three patients underwent additional treatments and achieved complete occlusion. Mean clinical follow-up duration was 32 months and results were modified Rankin Scale 1-2 in five, 3-4 in five, and 5 in three patients.

Conclusion : The covered stent could be considered as fist line treatment option for treating TCCF patients especially in unstable vital sign. Larger samples and expanded follow-up are required to further develop their specifications and indications.

Key Words : Traumatic carotid cavernous sinus fistula · Covered stent · Treatment.

\section{INTRODUCTION}

Direct carotid cavernous fistula (DCCF) is a direct communication between the internal carotid artery (ICA) and cavernous sinus (CS). DCCF is caused by head and facial trauma or cavernous ICA aneurysm rupture; traumatic CCF (TCCF) accounts for approximately $75 \%$ of all direct CCF cases $^{30)}$. The arteriovenous shunt between ICA and CS leads to various signs and symptoms including exophthalmos, chemosis, decreased visual acuity, cranial nerve impairment, or life-threatening hemorrhage and epistaxis. However, these characteristics are similar to those of multiple head and facial trauma. Hence, the diagnosis of TCCF may be delayed.

At present, endovascular therapy is the mainstay treatment for TCCF. TCCF is primarily treated with parent artery occlusion, which is a deconstructive method and can be performed

- Received : December 11, 2020 •Revised : March 3, 2021 •Accepted : April 7, 2021

- Address for reprints : Jae II Lee

Department of Neurosurgery, Pusan National University Hospital, Pusan National University School of Medicine, 179 Gudeok-ro, Seo-gu, Busan 49241, Korea Tel : +82-51-240-7257, Fax : +82-51-244-0282, E-mail : medifirst@pusan.ac.kr, ORCID : https://orcid.org/0000-0003-1412-4146 
in patients with good collateral flow. Reconstructive methods and fistula occlusion with detachable balloons or coils are therapeutic options for failed balloon test occlusion. The use of covered stents, which is another reconstructive treatment option for direct CCF, with encouraging short-to-midterm clinical outcomes, has recently emerged. Hence, the present study aimed to present the diagnosis of TCCF and the use of covered stents as the first-line treatment for TCCF in a level 1 regional trauma center.

\section{MATERIALS AND METHODS}

\section{Patient population}

The study was approved by the Institutional Review Board of Pusan National University Hospital (IRB No. H-2012-001-097). From November 2004 to February 2020, 19 covered stents were used for the treatment of 19 patients with TCCF. Among these patients, 15 underwent covered stent implantation as the firstline treatment (Graftmaster coronary stent graft system; Abbott Vascular, Rangendingen, Germany). The cohort comprised five women and 10 men with a mean age of 38.7 years (range, 1263). The mechanisms of injury were motor vehicular accident in three (20\%), motorcycle accident in seven (47\%), falling in four $(27 \%)$, and iatrogenic injury after pituitary adenoma surgery in one patient $(7 \%)$.

The clinical symptoms were categorized as orbital, cavernous, ocular, and cerebral. The orbital symptoms included chemosis, exophthalmos, periorbital pain, and eyelid swelling, which were caused by retrograde venous flow and/or pressure in CS. The cavernous symptoms were ptosis, diplopia, anisocoria, and ophthalmoplegia, and they were attributed to cranial nerve deficits. Meanwhile, the ocular symptoms correlated with increased venous pressure caused by eyeball draining included decreased vision, increased intraocular pressure, glaucoma, and retinal hemorrhage. The cerebral symptoms were correlated with reflux from the arteriovenous shunt into the superficial middle cerebral vein or the petrosal vein into the perimesencephalic and cerebellar veins. This then leads to infarction or venous congestion in the basal ganglia, brain stem, or cerebellum, which causes seizure or hemorrhage $e^{36)}$. According to symptom classification, 10, five, seven, and two patients presented with orbital, cavernous, ocular, and cerebral symptoms, respectively. Meanwhile, two patients experi- enced life-threatening epistaxis and three had intracranial hemorrhage.

In our trauma center, the indications of covered stent insertion are as follows : 1) large size CCF (high flow shunting), 2) life-threatening epistaxis, 3) life-threatening intracranial hemorrhage, and 4) severe cortical venous reflux. Chi et al. ${ }^{4)}$ described size of CCF according to opacification of anterior cerebral artery (ACA) and middle cerebral artery (MCA) on angiography. Angiograms with opacification of both MCA and MCA were categorized as small size fistula. Angiograms with opacification of either ACA or MCA were categorized as medium size fistula and those without opacification of neither ACA nor MCA were classified as large size fistula. The outcomes immediately after the procedure were classified as total occlusion (no residual shunt), near-total occlusion (minimal residual shunt), and subtotal occlusion (high flow residual shunt). In total, 13 patients underwent follow-up clinical examination and imaging (angiography, computed tomography angiography, or magnetic resonance angiography; Table 1).

\section{Endovascular procedure}

All procedures were performed under local anesthesia with light sedation. Angiographic evaluation included ipsilateral and contralateral carotid and vertebral angiographies with neck (carotid) compression. Vertebral angiography with ipsilateral ICA compression was extremely effective in identifying the exact fistula points (vertical, genu, and horizontal) of the cavernous ICA. The access was made through the right femoral artery. Then, a 6-F $80-\mathrm{cm}$ long sheath (Shuttle Sheath; Cook, Bloomington, IN, USA) was inserted. After sheath insertion, heparin sodium $3000 \mathrm{IU} / \mathrm{mL}$ was administered as a bolus for systemic heparinization and heparin sodium 1000 $\mathrm{IU} / \mathrm{mL}$ as a bolus every hour to maintain an activated clotting time of 250-300 seconds, except for patients with high-risk hemorrhage. The Shuttle Sheath was located in the distal cervical ICA, and a 6-F guide catheter or intermediate catheter was inserted into the sheath and positioned in the cavernous ICA segment. Subsequently, the microwire was navigated into the second or third segment of the middle cerebral artery. The Graftmaster coronary stent graft system sized 4/19 mm (Abbott Vascular, Rangendingen, Germany) was then advanced over the microwire and placed at the fistula point. Then, the stent was deployed with staged ballooning to achieve a suitable apposition between the stent and vessel wall. If endoleak 
Table 1. Summary of the patients' data

\begin{tabular}{|c|c|c|c|c|c|c|c|c|c|}
\hline No. & Age & Sex & $\begin{array}{c}\text { Trauma } \\
\text { mechanism }\end{array}$ & Initial GCS & Presentation & $\begin{array}{l}\text { Basal skull } \\
\text { fracture }\end{array}$ & Fistula point & $\begin{array}{l}\text { Size of } \\
\text { fistula }\end{array}$ & $\begin{array}{c}\text { Cortical } \\
\text { venous } \\
\text { reflux }\end{array}$ \\
\hline 1 & 36 & $M$ & $\mathrm{FD}$ & 15 & $1^{*}, 2^{\dagger}, 3^{\ddagger}$ & - & Lt ICAPG & Large & + \\
\hline 2 & 63 & M & FD & 3 & Life threatening epistaxis & + & Lt ICAPG & Small & - \\
\hline 3 & 52 & M & $\mathrm{FD}$ & 15 & $1^{*}, 2^{\dagger}, 3^{\ddagger}$ & - & Lt ICAPG & Large & - \\
\hline 4 & 12 & M & FD & 15 & $1^{*}, 2^{\dagger}, 3^{\ddagger}$ & + & Lt ICAPG & Large & + \\
\hline 5 & 17 & M & MCC & 3 & Life threatening $\mathrm{ICH}$ & - & Lt ICAPG & Small & - \\
\hline 6 & 31 & M & MCC & 8 & Life threatening $\mathrm{ICH}_{1} 1^{*}, 3^{\ddagger}$ & + & Rt ICAPG & Small & - \\
\hline 7 & 52 & M & MCC & 13 & $1^{*}, 2^{\dagger}$ & + & Lt ICA PG & Small & + \\
\hline 8 & 23 & M & MCC & 4 & $1^{*}, 3^{\ddagger}$ & + & Rt ICAPG & Large & - \\
\hline 9 & 62 & $\mathrm{~F}$ & MVC & 7 & $1^{*}, 3^{\ddagger}, 4^{\S}$ & + & Lt ICAPG & Large & - \\
\hline 10 & 22 & M & MCC & 7 & $1^{*}, 2^{\dagger}$ & + & Lt ICAPG & Medium & + \\
\hline 11 & 18 & M & MCC & 3 & $3^{\ddagger}, 4^{\S}$ & + & Lt ICAPG & Large & + \\
\hline 12 & 54 & $\mathrm{~F}$ & latrogenic & 12 & Life threatening epistaxis & - & Lt ICA horizontal & Small & - \\
\hline 13 & 58 & $\mathrm{~F}$ & MVC & 7 & $1^{*}$ & + & Lt ICAPG & Large & - \\
\hline 14 & 18 & $\mathrm{~F}$ & MCC & 5 & Life threatening $\mathrm{ICH}$ & + & Rt ICA anterior genu & Small & + \\
\hline 15 & 63 & $\mathrm{~F}$ & MVC & 9 & Life threatening $\mathrm{ICH}_{1} \mathrm{1}^{*}$ & + & Rt ICAPG & Small & - \\
\hline
\end{tabular}

*Orbital symptom. ${ }^{\dagger}$ Cavernous symptom. ${ }^{\ddagger}$ Ocular symptom. ${ }^{\circledR}$ Cerebral symptom. GCS : Glasgo coma scale, M : male, FD : fall down, Lt : left, ICA : internal carotid artery, PG : posterior genu, MCC : motorcycle crash, ICH : intracranial hemorrhage, Rt : right, F : female, MVC : motor vehicle crash

occurred, multiple balloon inflation (3 to 5 times) was performed by applying a higher to bursting pressure or using a larger balloon. Additional endoleak point coil occlusion with or without a bare stent was applied in most cases of subtotal occlusion after multiple balloon angioplasties.

All patients except emergent cases were premedicated with aspirin $100 \mathrm{mg} /$ day and clopidogrel $75 \mathrm{mg} /$ day orally for 7 days before the procedure. After the procedure, patients with low risk of acute bleeding received aspirin $100 \mathrm{mg}$ and clopidogrel $75 \mathrm{mg}$ for 6 months, followed by $75 \mathrm{mg}$ clopidogrel for $>1$ year.

\section{RESULTS}

The procedures were technically successful in all 15 cases. After covered stent deployment with maximum multiple balloon inflation, endoleak still occurred in six patients (40\%). Of these patients, five underwent additional endovascular treatment and one who had minimal endoleak underwent follow-up imaging. Additional fistula point occlusion was achieved using detachable coils $(\mathrm{n}=2)$, proximal bare stenting $(\mathrm{n}=1)$, stent-assisted coiling $(\mathrm{n}=1)$, and second covered stenting $(\mathrm{n}=1)$. Immediate angiographic outcomes after the procedure were total occlusion $(n=12,80 \%)$, near-total occlusion $(n=2$, $13 \%)$, and subtotal occlusion ( $\mathrm{n}=1,7 \%)$. All patients, except two who died due to multiple severe traumas, underwent follow-up imaging (range, 2 days to 4 years; mean, 15 months). Three patients presented with recurrence, which was completely occluded during the initial procedure. All patients with recurrence received additional treatments (transvenous CS occlusion, stent-assisted coiling via a distal endoleak point, and balloon angioplasty) and achieved complete occlusion. The patients underwent clinical follow-up (range, 2-108 months; mean, 32 months). During follow-up, the outcomes were mild, moderate, and severe in five, five, and three patients (modified Rankin Scale scores of 1-2, 3-4, and 5, respectively), respectively (Table 2).

\section{Illustrative cases}

\section{Patient 11}

An 18-year-old male who presented with left-sided exophthalmos and ptosis 48 days after a motorcycle accident was 


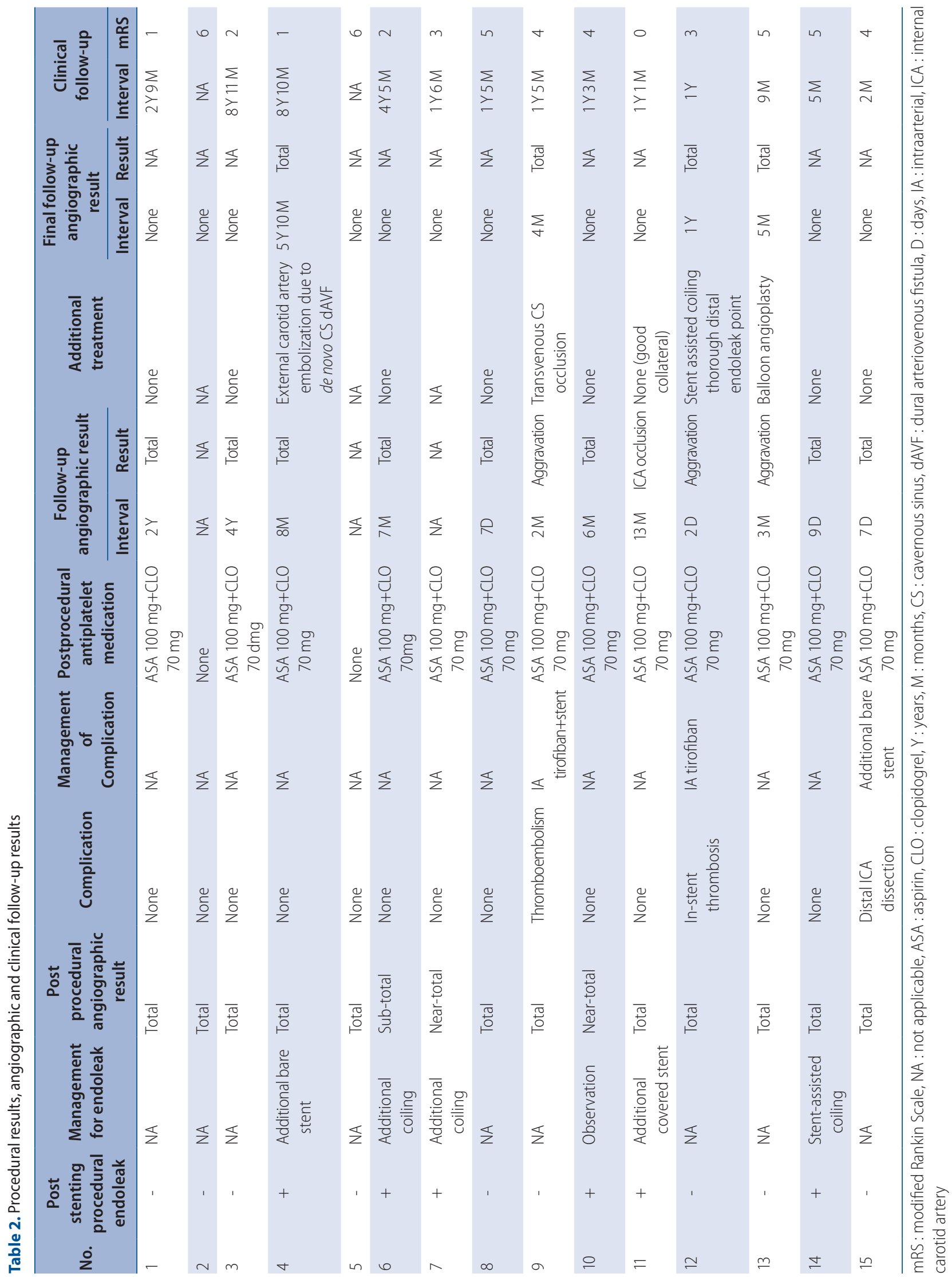


admitted for the treatment of TCCF. The fistula point was at the posterior genu of the cavernous ICA. Then, a covered stent was advanced to the fistula, and repeated balloon dilatation was performed with gradually increasing pressure. After maximum trial of balloon angioplasty, endoleak persisted at the proximal end of the stent, and the wall apposition of the stent was not good. Then, additional overlapping covered stenting (same size) using the telescoping technique was performed. After the second stent deployment, final angiogram showed complete occlusion of CCF. The patient fully recovered (Fig. 1).

\section{Patient 12}

A 54-year-old female patient who presented with life-threat- ening epistaxis after transsphenoidal pituitary adenoma surgery was transferred from another institution in the province to our hospital. The patient had unstable vital signs, and computed tomography angiography revealed iatrogenic TCCF with pseudoaneurysm formation at the horizontal segment of the cavernous ICA. Emergency covered stent deployment was performed at the fistula; then, complete occlusion of CCF was achieved. However, she presented with recurrent epistaxis 2 days after the covered stent procedure, and angiography confirmed endoleak at the distal end of the stent. After repeated balloon angioplasty, imaging revealed decreased fistula flow. However, remnant flow was still observed. Microcatheter insertion via the fistula point at the distal end of the stent and additional stent-assisted coiling (Solitaire AB 6/30 stent; Covi-
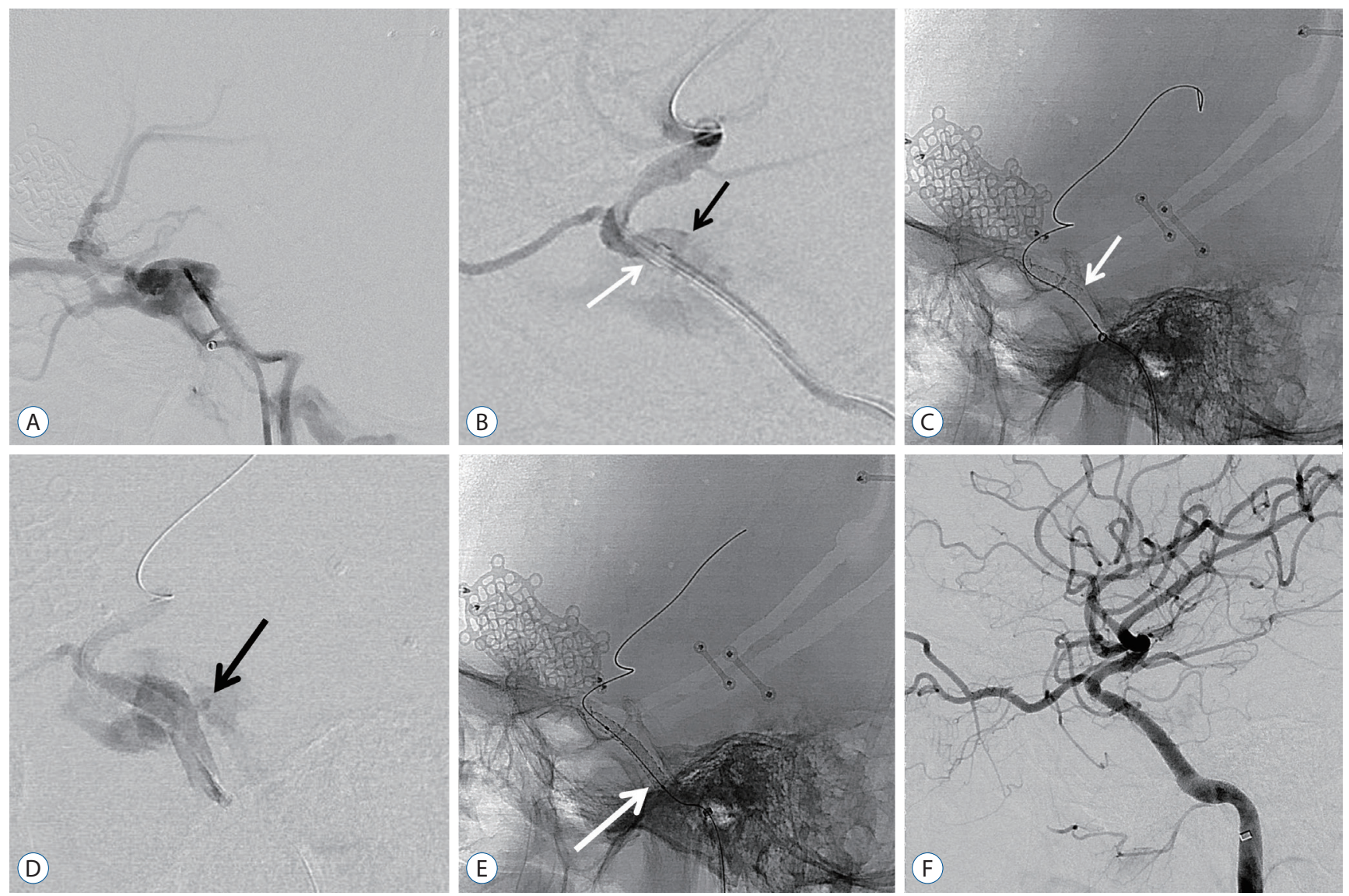

Fig. 1. An 18-year-old man with left-sided exophthalmos and ptosis in 48 days after motor cycle accident. A : Lateral digital subtraction image of left ICA showing the presence of a TCCF draining via the superior ophthalmic vein, pterygoid plexus, and petrosal sinuses. $B$ : Lateral angiography after distal access guiding catheter (white arrow) delivery to anterior genu of cavernous ICA. Black arrow demonstrated rupture site of ICA. C : Lateral radiography demonstrating deployment of covered stent and white arrow indicated proximal end of the stent. D : Immediate post-procedural angiography confirmed endoleak at proximal end of the stent due to size mismatch. Black arrow confirmed endoleak point. $E$ : Lateral radiography showing additional overlapping covered stent (white arrow) using telescoping technique. F : Final angiogram demonstrating complete occlusion of TCCF. ICA : internal carotid artery, TCCF : traumatic carotid cavernous fistula. 
dien, Irvine, CA, USA) were performed. After complete occlusion of the fistula point, the patient's vital signs improved significantly, and she was discharged with mild vision impairment (Fig. 2).

\section{DISCUSSION}

The actual incidence of TCCF is not fully elucidated. Several studies have reported that the incidence ranges from $0.17 \%$ to $1.01 \%$ in patients with traumatic head and facial trauma ${ }^{37,44)}$ and is up to $4 \%$ in those with basal skull fractures ${ }^{27)}$. TCCF could result in permanent neurologic impairment or even death if untreated. Thus, treatment is required to relieve symptoms and control massive bleeding. Nevertheless, the symptoms of TCCF may be masked in patients with head and facial trauma. Hence, its diagnosis could be delayed. TCCF should be considered, and patients with severe head and facial trauma must undergo imaging during the initial evaluation. In our trauma center, computed tomography angiography is performed based on the Denver criteria ${ }^{11,17)}$.

Although parent artery occlusion was performed in the early stages, the outcomes were not satisfactory. In other words, even if patients had good tolerance to balloon test occlusion, the ischemic complication rates ranged from $5 \%$ to $22 \%{ }^{3,21)}$. Then, a detachable balloon was introduced to prevent fistula formation without parental artery occlusion, and the success rate was $88-98 \% \%^{7,10,15,20,23,24,29,31,35)}$. Hence, this method was considered the primary treatment. With the advent of endovascular techniques, the use of detachable coils combined with bare stents has been proven to be an excellent therapeutic strategy for the treatment of DCCF ${ }^{1,4,19,28,29,33,39)}$. Although they are excellent therapeutic devices, they cannot be used in some cases, which include an extremely large orifice to cover with detachable balloons or coils and sharp osseous fragments within the sinus that cause premature balloon deflation. Moreover, these devices have disadvantages. That is, there is a risk of cranial nerve palsy caused by mass effect. Furthermore, parental artery occlusion or ischemic events caused by coil migration could occur ${ }^{8,13,18,20,23,39)}$. Currently, the use of detachable balloons may also be limited by their availability ${ }^{12)}$.

A recent study used a covered stent in DCCF and reported the outcomes ${ }^{2,5,12,16,25,26,38,40,41)}$. Covered stents can be used in some conditions in which detachable balloons and coils cannot be utilized. The reported success rate to date of detachable balloon, flow diverter and covered stent for occlusion of TCCF
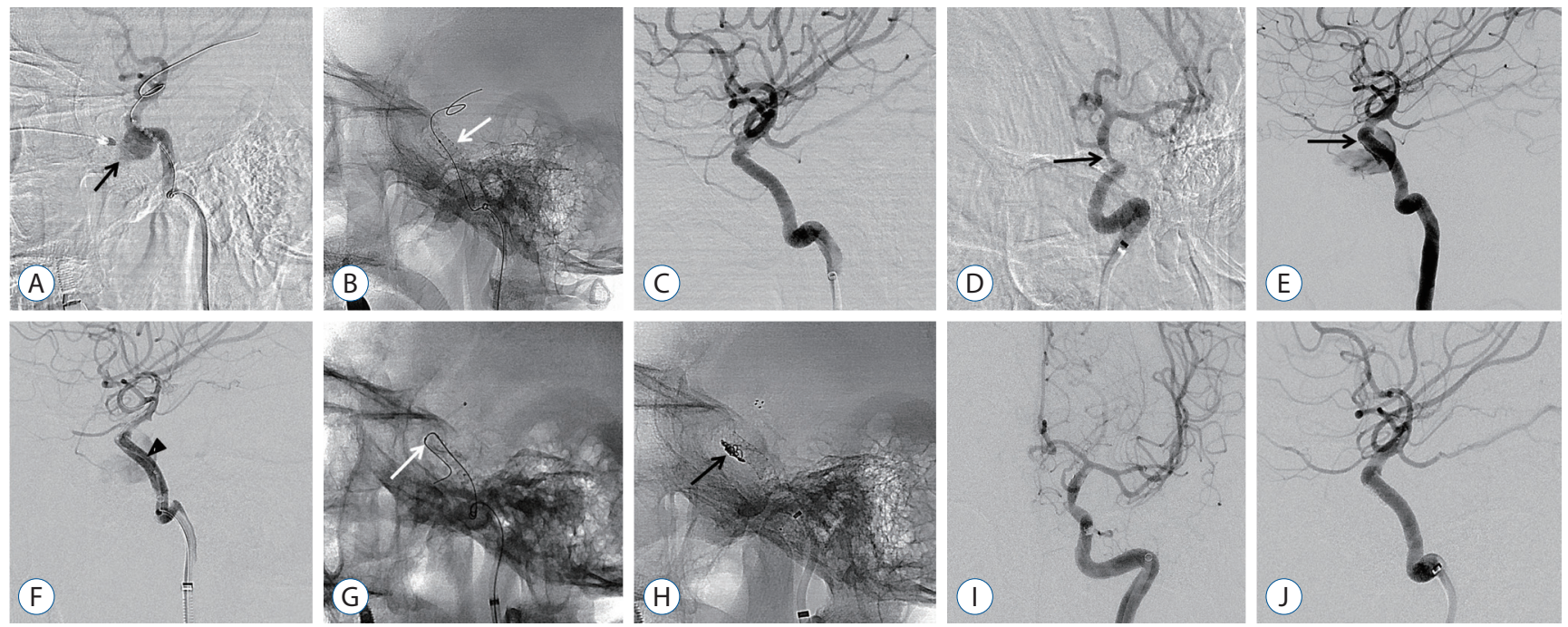

Fig. 2. A 54-year-old female with life threatening epistaxis after transsphenoidal pituitary adenoma surgery. A : Lateral angiogram of left ICA demonstrating iatrogenic TCCF with pseudoaneurysm formation (black arrow) at horizontal segment of cavernous ICA. B and C: After the covered stent was deployed (white arrow), complete occlusion of CCF was confirmed. D : Oblique delayed angiography after covered stent deployment showed ICA stenosis distal to the stent, which confirmed vasospasm (black arrow). E : Recurrent epistaxis developed 2 days after covered stent treatment and angiography confirmed endoleak at distal end of the stent (black arrow). F : After repeated balloon angioplasty (black arrowhead), angiography showed a decrease of fistula flow but still persisted. $\mathrm{G}$ and $\mathrm{H}$ : Microcatheter (white arrow) selection through fistula point at distal end of the stent and additional stent assisted coiling was done (black arrow). I and J : Follow-up anterior and lateral angiography showed stable occlusion of fistula. ICA : internal carotid artery, TCCF : traumatic carotid cavernous fistula. 
as primary treatment modality was $55-98 \%^{8,14,20)}, 71 \%{ }^{42)}$, and $75-100 \%{ }^{12,26,41)}$, respectively and our results were similar with previous reports. Moreover, it has advantages in the concept of one-step and time-saving treatment in emergency situations. The Graftmaster coronary stent graft system described in this study was originally designed for the management of coronary perforations in relatively straight coronary ves$\operatorname{sels}^{2,34,41)}$. Therefore, there is a limit in the application of covered stents with a stiff delivery system to the tortuous cavernous ICA system, which causes endoleak. This condition was correlated with poor stent vessel apposition or size mismatch. Previously, endoleak was expected to disappear and was not actively treated. If endoleak persisted in follow-up imaging, additional second bare stent placement or CS occlusion was performed $^{2,5,12,16,25,26,38,40,41)}$. We completed the first procedure with total occlusion in all patients, except in three with tolerable remnant endoleak. On follow-up imaging, three patients who had complete occlusion during the initial procedures presented with CCF recurrence. According to a root cause analysis, one patient who had low volume status was admitted due to severe epistaxis after surgery for pituitary adenoma. Due to excessive blood loss, the ICA collapsed and the covered stent was positioned in the temporarily constricted vessel. After volume resuscitation, vasospasm was treated and size mismatch between the covered stent and the dilated vessel caused endoleak. In another case, endoleak was believed to be attributed to incomplete apposition between the covered stent and the vessel wall at the proximal end. According to a previous study, the incidence of endoleak varies from $9 \%$ to $83 \%{ }^{16,25,26,34,40)}$.

To reduce the incidence rate of endoleak without destructive procedure such as CS occlusion, some techniques including balloon angioplasty and use of longer and oversized covered stents were applied ${ }^{16,25,26,40)}$. If the endoleak persisted in such attempts, we sealed the endoleak with a microcatheter via the leakage point and occluded it with detachable coils. Herein, we reported four cases of fistula point microselection and coil occlusion for endoleak, three of which were performed at the time of primary covered stent placement and one during the subsequent angiography after the placement of a covered stent. There might be limitations in vessel wall apposition due to shape and size mismatch, particularly at the proximal and distal ends, which usually cause type 1 endole$\mathrm{ak}^{16,43)}$.
Endovascular aortic aneurysm repair for anatomically suitable abdominal aortic aneurysms has gained wide acceptance in the past decade ${ }^{9)}$, and some studies have performed prophylactic proximal bare stent placement in hostile necks because patients with such anatomy are at an increased risk of proximal endoleak (type 1a) and migration, resulting in adverse events in up to $70 \%$ of cases ${ }^{6,22,32}$. We believe that prophylactic bare stent placement might also be applied to an intracranial covered stent. One patient with recurrent symptoms experienced complete occlusion during the initial procedure. However, the final angiographic imaging showed proximal end mismatch. Thus, endoleak was likely to occur, which could have been prevented with a prophylactic bare stent (patient number 13). The placement of prophylactic bare stent could maximize apposition of the covered stent to the vessel wall, and the use of a prophylactic bare stent with or without endoleak during the initial procedure is believed to reduce the rate of postprocedural endoleak. The limitations of present study include its retrospective nature, the recruitment of a limited number of patients, and relatively short follow-up duration. However, we presented indications of covered stent as a first-line treatment for TCCF and stent-based intracranial artery reconstruction could become the first-line treatment modality for TCCF.

\section{CONCLUSION}

TCCF is fatal and life-threatening; therefore, it must be considered and diagnosed in patients with severe head and facial trauma. Covered stent is the most reconstructive method, with a high total occlusion rate. Although endoleak has been the primary concern in the use of a covered stent, it could be managed with detachable coils at the leakage point or prophylactic bare stent in specific cases. Covered stents could be considered as the first-line treatment for TCCF. However, long-term follow-up and larger-scale studies are still warranted to further develop the specifications and indications of such device.

\section{CONFLICTS OF INTEREST}

No potential conflict of interest relevant to this article was reported. 


\section{INFORMED CONSENT}

This type of study does not require informed consent.

\section{AUTHOR CONTRIBUTIONS}

\author{
Conceptualization : JIL \\ Data curation : $\mathrm{SHJ}$ \\ Formal analysis : $\mathrm{SHJ}$ \\ Funding acquisition : JIL \\ Methodology : SHY \\ Project administration : BCK \\ Visualization : JIL \\ Writing - original draft : SHJ \\ Writing - review \& editing : JHL, HJC
}

\section{ORCID}

Sang Hoon Jeong https://orcid.org/0000-0002-9595-053X Jung Hwan Lee https://orcid.org/0000-0002-1393-7105

Hyuk Jin Choi https://orcid.org/0000-0001-9806-8676

Byung Chul Kim https://orcid.org/0000-0002-0439-1382

Seung Han Yu https://orcid.org/0000-0003-0086-3204

Jae Il Lee https://orcid.org/0000-0003-1412-4146

\section{- Acknowledgements}

This work was supported by Biomedical Research Institute Grant (2021) of Pusan National University Hospital.

\section{References}

1. Ahn JY, Lee BH, Joo JY : Stent-assisted Guglielmi detachable coils embolisation for the treatment of a traumatic carotid cavernous fistula. J Clin Neurosci 10 : 96-98, 2003

2. Archondakis E, Pero G, Valvassori L, Boccardi E, Scialfa G : Angiographic follow-up of traumatic carotid cavernous fistulas treated with endovascular stent graft placement. AJNR Am J Neuroradiol 28 : 342-347, 2007

3. Carter BS, Ogilvy CS, Putman C, Ojemann RG : Selective use of extracranial-intracranial bypass as an adjunct to therapeutic internal carotid artery occlusion. Clin Neurosurg 46 : 351-362, 2000

4. Chi CT, Nguyen D, Duc VT, Chau HH, Son VT : Direct traumatic carotid cavernous fistula: angiographic classification and treatment strategies. Study of 172 cases. Interv Neuroradiol 20 : 461-475, 2014

5. Choi BJ, Lee $\mathrm{TH}, \mathrm{Kim}$ CW, Choi CH : Endovascular graft-stent placement for treatment of traumatic carotid cavernous fistulas. J Korean Neurosurg Soc 46 : 572-576, 2009

6. Cox DE, Jacobs DL, Motaganahalli RL, Wittgen CM, Peterson GJ : Outcomes of endovascular AAA repair in patients with hostile neck anatomy using adjunctive balloon-expandable stents. Vasc Endovascular Surg $40: 35-40,2006$

7. Debrun $G$, Lacour P, Caron JP, Hurth M, Comoy J, Keravel Y : Detachable balloon and calibrated-leak balloon techniques in the treatment of cerebral vascular lesions. J Neurosurg 49 : 635-634, 1978

8. Debrun G, Lacour P, Vinuela F, Fox A, Drake CG, Caron JP : Treatment of 54 traumatic carotid-cavernous fistulas. J Neurosurg 55 : 678-692, 1981

9. Diethrich EB : The bumpy road is over. Endoluminal grafts for abdominal aortic aneurysm repair will be the gold standard. J Cardiovasc Surg (Torino) 47 : 235-237, 2006

10. Fattahi TT, Brandt MT, Jenkins WS, Steinberg B : Traumatic carotidcavernous fistula: pathophysiology and treatment. J Craniofac Surg $14: 240-246,2003$

11. Geddes AE, Burlew CC, Wagenaar AE, Biffl WL, Johnson JL, Pieracci FM, et al. : Expanded screening criteria for blunt cerebrovascular injury: a bigger impact than anticipated. Am J Surg 212 : 1167-1174, 2016

12. Gomez F, Escobar W, Gomez AM, Gomez JF, Anaya CA : Treatment of carotid cavernous fistulas using covered stents: midterm results in seven patients. AJNR Am J Neuroradiol 28 : 1762-1768, 2007

13. Gupta AK, Purkayastha S, Krishnamoorthy T, Bodhey NK, Kapilamoorthy TR, Kesavadas C, et al. : Endovascular treatment of direct carotid cavernous fistulae: a pictorial review. Neuroradiology 48 : 831-839, 2006

14. Higashida R, Halbach V, Tsai F, Norman D, Pribram H, Mehringer C, et al. : Interventional neurovascular treatment of traumatic carotid and vertebral artery lesions: results in 234 cases. Am J Roentgenol 153 : 577582, 1989

15. Higashida RT, Halbach VV, Dowd C, Barnwell SL, Dormandy B, Bell J, et al. : Endovascular detachable balloon embolization therapy of cavernous carotid artery aneurysms: results in 87 cases. J Neurosurg 72 : 857863, 1990

16. Hoit DA, Schirmer CM, Malek AM : Stent graft treatment of cerebrovascular wall defects: intermediate-term clinical and angiographic results. Neurosurgery 62 : ONS380-ONS388; discussion ONS388-ONS389, 2008

17. Kim DY, Biffl W, Bokhari F, Brakenridge S, Chao E, Claridge JA, et al. : Evaluation and management of blunt cerebrovascular injury: a practice management guideline from the Eastern Association for the Surgery of Trauma. J Trauma Acute Care Surg 88 : 875-887, 2020

18. Klisch J, Schipper J, Husstedt H, Laszig R, Schumacher M : Transsphenoidal computer-navigation-assisted deflation of a balloon after endovascular occlusion of a direct carotid cavernous sinus fistula. AJNR Am J Neuroradiol 22 : 537-540, 2001 
19. Klisch J, Huppertz HJ, Spetzger U, Hetzel A, Seeger W, Schumacher M : Transvenous treatment of carotid cavernous and dural arteriovenous fistulae: results for 31 patients and review of the literature. Neurosurgery 53 : 836-856; discussion 856-857, 2003

20. Kobayashi N, Miyachi S, Negoro M, Suzuki O, Hattori K, Kojima T, et al. : Endovascular treatment strategy for direct carotid-cavernous fistulas resulting from rupture of intracavernous carotid aneurysms. AJNR Am J Neuroradiol 24 : 1789-1796, 2003

21. Kupersmith MJ, Hurst R, Berenstein A, Choi IS, Jafar J, Ransohoff J : The benign course of cavernous carotid artery aneurysms. J Neurosurg 77 : 690-693, 1992

22. Law Y, Chan YC, Cheng SW : Effectiveness of proximal intra-operative salvage Palmaz stent placement for endoleak during endovascular aneurysm repair. Hong Kong Med J 22 : 538-545, 2016

23. Lewis Al, Tomsick TA, Tew JM Jr : Management of 100 consecutive direct carotid-cavernous fistulas: results of treatment with detachable balloons. Neurosurgery 36 : 239-244; discussion 244-245, 1995

24. Lewis Al, Tomsick TA, Tew JM Jr, Lawless MA : Long-term results in direct carotid-cavernous fistulas after treatment with detachable balloons. J Neurosurg 84 : 400-404, 1996

25. Li J, Lan ZG, Xie XD, You C, He M : Traumatic carotid-cavernous fistulas treated with covered stents: experience of 12 cases. World Neurosurg 73 : 514-519, 2010

26. Li K, Cho YD, Kim KM, Kang HS, Kim JE, Han MH : Covered stents for the endovascular treatment of a direct carotid cavernous fistula : single center experiences with 10 cases. J Korean Neurosurg Soc 57 : 1218,2015

27. Liang W, Xiaofeng Y, Weiguo L, Wusi Q, Gang S, Xuesheng Z : Traumatic carotid cavernous fistula accompanying basilar skull fracture: a study on the incidence of traumatic carotid cavernous fistula in the patients with basilar skull fracture and the prognostic analysis about traumatic carotid cavernous fistula. J Trauma 63 : 1014-1020; discussion 1020, 2007

28. Lu X, Hussain M, Ni L, Huang Q, Zhou F, Gu Z, et al. : A comparison of different transarterial embolization techniques for direct carotid cavernous fistulas: a single center experience in 32 patients. J Vasc Interv Neurol 7 : 35-47, 2014

29. Luo CB, Teng MM, Yen DH, Chang FC, Lirng JF, Chang CY : Endovascular embolization of recurrent traumatic carotid-cavernous fistulas managed previously with detachable balloons. J Trauma 56 : 1214-1220, 2004

30. Mahalingam HV, Mani SE, Patel B, Prabhu K, Alexander M, Fatterpekar $\mathrm{GM}$, et al. : Imaging spectrum of cavernous sinus lesions with histopathologic correlation. Radiographics 39 : 795-819, 2019

31. Prolo DJ, Hanbery JW : Intraluminal occlusion of a carotid-cavernous sinus fistula with a balloon catheter. Technical note. J Neurosurg 35 : 237-242, 1971
32. Qu L, Raithel D : Experience with the endologix powerlink endograft in endovascular repair of abdominal aortic aneurysms with short and angulated necks. Perspect Vasc Surg Endovasc Ther 20 : 158-166, 2008

33. Remonda $L$, Frigerio SB, Bühler $R$, Schroth $G$ : Transvenous coil treatment of a type a carotid cavernous fistula in association with transarterial trispan coil protection. AJNR Am J Neuroradiol 25 : 611-613, 2004

34. Saatci I, Cekirge HS, Ozturk MH, Arat A, Ergungor F, Sekerci Z, et al. : Treatment of internal carotid artery aneurysms with a covered stent: experience in 24 patients with mid-term follow-up results. AJNR Am J Neuroradiol 25 : 1742-1749, 2004

35. Serbinenko FA : Reconstruction of the cavernous section of the carotid artery in carotid-cavernous anastomosis. Vopr Neirokhir $36: 3-8$, 1972

36. Suh DC, Lee JH, Kim SJ, Chung SJ, Choi CG, Kim HJ, et al. : New concept in cavernous sinus dural arteriovenous fistula: correlation with presenting symptom and venous drainage patterns. Stroke 36 : 1134-1139, 2005

37. Takenoshita Y, Hasuo K, Matsushima T, Oka M : Carotid-cavernous sinus fistula accompanying facial trauma. Report of a case with a review of the literature. J Craniomaxillofac Surg $18: 41-45,1990$

38. Tiewei Q, Ali A, Shaolei G, Feng L, Zhongsong S, Xuesong L, et al. : Carotid cavernous fistulas treated by endovascular covered stent grafts with follow-up results. Br J Neurosurg 24 : 435-440, 2010

39. van Rooij WJ, Sluzewski M, Beute GN : Ruptured cavernous sinus aneurysms causing carotid cavernous fistula: incidence, clinical presentation, treatment, and outcome. AJNR Am J Neuroradiol 27 : 185-189, 2006

40. Wang C, Xie X, You C, Zhang C, Cheng M, He M, et al. : Placement of covered stents for the treatment of direct carotid cavernous fistulas. AJNR Am J Neuroradiol 30 : 1342-1346, 2009

41. Wang YL, Ma J, Ding PX, Li YD, Han XW, Wu G : Treatment of posttraumatic carotid-cavernous fistulas with the Willis covered stent. A preliminary prospective study. Interv Neuroradiol 18 : 172-177, 2012

42. Wendl CM, Henkes $H$, Martinez Moreno R, Ganslandt O, Bäzner $H_{\text {, }}$ Aguilar Pérez $M$ : Direct carotid cavernous sinus fistulae: vessel reconstruction using flow-diverting implants. Clin Neuroradiol 27 : 493501, 2017

43. White GH, Yu W, May J : Endoleak--a proposed new terminology to describe incomplete aneurysm exclusion by an endoluminal graft. J Endovasc Surg 3 : 123-125, 1996

44. Zachariades N, Papavassiliou D : Traumatic carotid-cavernous sinus fistula. J Craniomaxillofac Surg 16 : 385-388, 1988 